\title{
CALUNDUS: A ALIMENTAÇÃO E A CURA
}

\author{
Calundu - Grupo de Estudos sobre Religiões Afro-Brasileiras ${ }^{1}$ \\ DOI 10.26512/revistacalundu.v3i1.25242
}

As práticas de alimentação e do consumo dos produtos da terra com fins terapêuticos e de restauração preventiva do equilíbrio para a saúde também demonstram como ocorreu o encontro afro-ameríndio no Brasil, através da formação e perpetuação de hábitos alimentares e remédios tradicionais, seja na medicina caseira ou em rituais de cura.

Fora dos grandes ciclos de produção da cana-de-açúcar e depois do café, que abasteceram os mercados mundiais e que restringiam a produção de víveres no país, a alimentação cotidiana das pessoas comuns nas terras brasileiras foi se formando em trocas que escapavam ao estilo de vida português civilizatório instaurado no período colonial, que era uma imposição, ou o recriavam, resistindo a ele. E depois, terminaram moldando o paladar até dos mais abastados, embora buscassem imitar os modos europeus trazidos para cá. Isto devido à grande presença de mulheres africanas e afrobrasileiras em suas cozinhas.

Entre as idas e vindas do comércio transatlântico nesse período de formação, espécies nativas e as trazidas para o Brasil fizeram surgir pequenos cultivos (roças, roçados), além do que já era feito pelos indígenas, ou eram recolhidas na própria natureza, nativas ou aclimatadas. Com o tempo, foram criadas nossas cozinhas regionais, mas alguns ingredientes tiveram um alcance maior, já desde cedo.

O encontro do Brasil com povos africanos pode ser lembrado pelo próprio nome de animais e vegetais comestíveis, como no caso da galinha d'angola. A galinha d'angola, (também conhecida como angolista, capote, cocar, conquém, guiné, galinha pintada) não apenas é modelo de enfeites artesanais, mas costuma ser criada em chácaras e fazendas para prevenir animais peçonhentos, já que tem o hábito de viver solta no mato.

\footnotetext{
${ }^{1}$ Texto de autoria coletiva elaborado para o projeto de extensão "Diálogos Comunitários Calunduzeiros", Fazem parte do projeto, em ordem alfabética: Adélia Regina da Silva Mathias, Aisha Angele Leandro Diéne, Andréa Letícia Carvalho Guimarães, Ariadne Moreira Basílio, Clara Jane Costa Adad, Danielle de Cássia Afonso Ramos, Francisco Phelipe Cunha Paz, Gerlaine Torres Martini, Guilherme Dantas Nogueira, Hans Carrillo Guach, Iyaromi Feitosa Ahualli, Luís Augusto Ferreira Saraiva, Nathalia Vince Esgalha Fernandes, Tania Mara Campos de Almeida.
} 
Dentro dos cultos afro-brasileiros, essa ave continua tendo um papel muito importante como comestível com funções terapêuticas, sendo utilizada nos principais ritos. Dessa forma, sua valorização nas comunidades de origem africana, quilombos, calundus e terreiros que iam se formando e resistindo à escravização, terminou gerando criações dessa ave, que se espalhou amplamente pelo território nacional.

A atual presença da assim chamada galinha d'angola, uma ave que povoava o continente africano, demonstra um elo muito antigo, pois alguns dos primeiros povos africanos que chegaram ao Brasil vieram da região da atual Angola. Por outro lado, a mandioca e o amendoim, plantas nativas de nosso território, foram levados para países da África. Quando aqui chegaram os europeus e africanos, eles já eram cultivados pelos povos originários ou nativos de nosso território, que hoje conhecemos como povos indígenas, sendo que mais de 200 povos diferentes (dos contatados) conseguiram sobreviver à colonização e hoje habitam 688 Terras Indígenas e áreas urbanas no território nacional, segundo dados reconhecidos oficialmente, sendo que podemos encontrar indígenas em todos os estados.

$\mathrm{O}$ amendoim se tornou um ingrediente bastante utilizado na culinária africana. Hoje em dia, em Angola, a pasta de amendoim pode entrar na receita da típica "muamba de galinha", um prato que lembra o frango com quiabo mineiro ou o xinxim de galinha baiano. Aqui, ele se encontra preservado também como ingrediente das oferendas das religiões afro-brasileiras, embora seu uso não seja tão conhecido na culinária afrorreligiosa como o da farinha de mandioca.

Os povos indígenas ao serem contatados pelos primeiros europeus já possuíam o saber do preparo da raiz de mandioca, como descascar, ralar, espremer, extrair a manipueira (sumo) e fazer a farinha. Podiam também preparar uma bebida alcoólica à base de mandioca que conhecemos como cauim, ainda preparado por diversos povos. Depois dos europeus, veio sua fabricação em casas de farinha com aparelhos ainda rústicos e sua disseminação nas terras africanas, através dos portugueses, holandeses e de navegantes brasileiros que assumiram as mesmas atividades mercantis, a farinha alimentando a tripulação e o contingente de africanos cativos trazidos para o Brasil.

Assim, a farinha de mandioca, de origem indígena, é a base que uniu o pirão brasileiro aos pratos tradicionais do funji ou matete em Angola e à iguaria chamada kuanga no Congo, receitas africanas feitas com ela, e que são regadas pelo tempero de molhos extraídos de peixes ou outras carnes. A farinha de mandioca também proporcionou o preparo das farofas, imprescindíveis nas oferendas e nas refeições em 
homenagem a determinadas entidades e divindades bastante conhecidas atualmente dos terreiros de umbanda e candomblé.

Alimento base dos povos indígenas antes da colonização, o uso tradicional da farinha de mandioca nas oferendas dos terreiros serve de termômetro para medir o quanto africanos e indígenas intercambiaram seus saberes e sabores. Essa mescla vinda de diferentes matrizes culturais tem em suas primeiras origens as aldeias e os povoados de pessoas escravizadas refugiadas em locais mais isolados ou relativamente próximos de núcleos urbanos, que formaram os quilombos antigos.

Alguns deles não existem mais, e sua localização ficava em áreas urbanas onde cresceram as cidades (como em bairros atuais de São Paulo ou Salvador). Outros permaneceram como comunidades de quilombo contemporâneas que ainda povoam nosso território (rurais e também dentro do perímetro de grandes cidades), num total de mais de três mil registros municipais de suas terras comunitárias, em quase todos estados, sendo as maiores concentrações regionais: Pará, Maranhão, Bahia, Minas Gerais, Goiás, Mato Grosso, Rio Grande do Sul.

Os antigos quilombos, territórios de resistência, contavam com a presença de populações indígenas próximas, pressionadas ou perseguidas, com modos de fazer e sobreviver indígenas também se fazendo presentes. Neles passaram a serem cultivados produtos em sua maior parte nativos das Américas ou africanos, como milho, determinados tipos de feijão, tubérculos (mandioca, batata-doce, carás ou inhame) e havia criações de cabras e galinhas somadas à caça e à pesca para subsistência. Documentos históricos demonstram como os quilombos podiam inclusive possuir espaço designado para moer os grãos e tubérculos, caracterizados como "casa de pilões", além de hortas.

As atuais comunidades dos territórios quilombolas ainda conservam muito desse cultivo tradicional, através de sementes crioulas (não geneticamente modificadas) e mudas tradicionais, apesar da pressão da urbanidade e de empreendimentos sobre seu ambiente e paisagem. Ainda utilizam o que produzem, em grande parte, em sua culinária. Seus doces de frutas açucaradas, assim como as bebidas tônicas e curtidas são iguarias comercializadas e bastante apreciadas por toda sociedade, mas também preparam tutus, paçocas (uma forma indígena de preparo), do fubá de milho angus, broas e farofas, que são alimentos conhecidos por prestigiar as festas populares em todo país. 
As comunidades de quilombos ainda podem surpreender com os sabores de cafés alternativos formados por grãos torrados de sucedâneos da coffe arábica (grão da Etiópia e do Iêmen que veio formar um ciclo de monocultura nestas paragens), mas que já eram conhecidos antes da cultura do café, como o feijão guandu (afro-indiano via o Congo) e o fedegoso ou manjerioba, planta daqui, mas que ocorre na África, também conhecida como "folha-de-pajé" (o curador indígena). Também lhe são atribuídas garrafadas e bebidas tônicas, aguardente curtida com especiarias, como a canjebrina, somadas aos chamados vinhos, como o de quiabo de angola (ou quiabo-roxo, caruru-daguiné, vinagreira - uma planta de folhas cor de vinho).

Interessante notar que algumas entidades homenageadas como ancestrais em terreiros de umbanda, candomblés, culto de encantados e casas de religião afro-indígena (dos mais conhecidos nacionalmente, os pretos-velhos/as e caboclos/as), costumam receber refeições no mesmo repertório culinário dos quilombos, principalmente milho, acrescidos dos subprodutos da cana-de-açúcar e do café, dos dois ciclos monocultores de alimentos.

Pretos e pretas-velhas incorporados gostam de saborear angus (semelhante ao funjí angolano feito com milho), vinhos (os tônicos quilombolas) e de tomar café, além de pitar em seus cachimbos. Da mesma forma, caboclos, como habitantes das matas ligados aos modos de sobreviver indígenas preferem os milhos cozidos, as frutas e o mel extraídos da vegetação nativa, mas não dispensam os gomos de cana e as meladinhas (misturas de aguardente, mel e ervas). Seus utensílios, as cuias e os coités, também são feitos a partir da vegetação da mata, onde sorvem seus alimentos enquanto conversam, aconselham e fumam tabaco.

O milho, ameríndio e muito presente (embora fosse conhecida uma variedade dele em terras africanas), entra também na composição de oferendas para grande parte das divindades dos candomblés, sendo branco, verde ou vermelho, geralmente cozido. Curiosamente, mungunzá quer dizer "milho cozido" na língua africana quimbunda. As famosas pipocas do Velho, divindade da terra e da cura, podem curar afecções cutâneas e outras doenças ao serem derramadas sobre a pessoa, dentro do enfoque medicinal do candomblé. Há bebidas feitas ao modo africano com o milho, como o aluá de milho.

O consumo do tabaco por entidades incorporadas durante as sessões de consulta (uma forma de terapia mental tradicional) e de cura, também chama a atenção. Mais uma vez, uma planta nativa que tem uso em rituais de estilo africano, denotando uma aproximação afro-indígena. O uso do fumo sempre esteve associado a práticas 
medicinais nas sociedades tradicionais indígenas, e a folha in natura continua sendo uma ferramenta de povos indígenas para limpar das doenças e melhorar a disposição geral. Esta aplicação do tabaco tem grande divulgação no contex to dos cultos brasileiros mais próximos da tradição indígena, que reúnem pajelança, torés, terecôs, pena e maracá, catimbós, juremas, jarê e algumas formas de umbanda. Mas também entra em oferendas de um grupo específico nos candomblés.

A folha do tabaco conhecida através dos indígenas tornou-se um hábito saboreado inclusive em terras africanas, servindo de moeda de troca para navios que iam permutá-la por mão de obra escravizada capturada na África, durante o período colonial. Negociantes baianos e pernambucanos dominavam este comércio, que durou mais de um século. O tabaco passou a ser cultivado e o que não ia para o mercado europeu era tratado com bastante melado de cana e enrolado para carregar os navios que iam para a costa africana.

O comércio de tabaco foi aos poucos sendo modificado por trocas relacionadas com o azeite de dendê africano no século XIX. Aqui se percebe o sentido inverso em que alimentos provenientes da África se instalaram definitivamente como parte da culinária nacional, como também o quiabo e modos de usar a pimenta. Muitos pratos emblemáticos, que foram primeiramente oferendas nos terreiros, são feitos com dendê. O acarajé, bolinho de feijão frito neste óleo nas ruas por mulheres vestidas a caráter, segundo a tradição religiosa dos terreiros, está inscrito hoje como patrimônio imaterial nacional.

O acompanhamento tradicional do acarajé, a pimenta, também tem origem numa história de permutas afro-brasileiras, de pimentas africanas com as nativas, das quais duas espécies domesticadas por indígenas antes da chegada dos europeus. A chamada malagueta africana (ou grão do paraíso) já era conhecida na Europa, e chegou a ser introduzida no Brasil; depois este nome passou às espécies de frutos compridos encontradas na América do Sul, posteriormente globalizados.

$\mathrm{Na}$ tradição religiosa, como as comidas não são valorizadas apenas pelo seu sabor, mas pelo significado delas em relação a forças divinas e à história dos ancestrais, o costume de oferecer presentes de comida aos que pertencem a este contexto fez com que a forma de serem feitas fosse preservada. Baseadas em tradições culturais anteriores e no que as próprias pessoas comiam no presente, as oferendas, no entanto, podiam retornar ao cardápio da refeição trivial do dia a dia, sendo readaptadas e se tornando pratos consagrados, como o acarajé. Dentro dos cultos, o alimento continua sendo 
substância que serve para vivificar a mente, prevenir o desequilíbrio e restaurar a saúde física, mediante sua utilização ritualizada (que não se restringe apenas à ingestão desse alimento), seguindo um padrão de classificação da liturgia daquele grupo específico.

De forma semelhante, as plantas medicinais são manejadas por raizeiros (que usam saberes próprios aos sistemas que baseiam os rituais embora não façam rituais necessariamente) e por sacerdotes das tradições acima mencionadas quando receitam banhos, chás, fazem defumações e oferendas ou proíbem o consumo de algo. $\mathrm{O}$ repertório afrorreligioso das ervas exibe ampla correspondência litúrgica e terapêutica do encontro entre saberes indígenas e africanos. Ao não encontrarem nas terras brasileiras os mesmos fitoterápicos que sabiam curar as aflições, os africanos realizaram substituições com plantas nativas e europeias aclimatadas, segundo padrão baseado numa perspectiva originalmente africana e em alguns casos indígena. Dessa forma surge uma criação propriamente afro-brasileira, que a alimentação entrelaçada com as formas de se cuidar e curar expressa em sua diversidade.

\section{Referências Bibliográficas}

ANJOS, Rafael Sanzio Araújo dos. Quilombos: Geografia Africana - Cartografia Étnica -Territórios Tradicionais. Brasília: Mapas Editora \& Consultoria, 2009.

BARROS, José Flávio Pessoa de. A floresta sagrada de Ossaim: o segredo das folhas. Rio de Janeiro: Pallas, 2011.

\& NAPOLEÃO, Eduardo. Ewé Orìsà: uso litúrgico e terapêutico dos vegetais nas casas de candomblé jêje-nagô. Rio de Janeiro: Bertrand Brasil, 1999.

BRASIL, Instituto do Patrimônio Histórico e Artístico Nacional. Ofício das Baianas de Acarajé (Dossiê IPHAN 6). Brasília: IPHAN, 2007.

BRASIL, Ministério do Desenvolvimento Social e Combate à Fome. Alimento: Direito Sagrado - Pesquisa Socioeconômica e Cultural de Povos e Comunidades Tradicionais de Terreiros. Brasília: MDS; Secretaria de Avaliação e Gestão da Informação, 2011.

CASCUDO, Luís da Câmara. História da Alimentação no Brasil. São Paulo: Global, 2004.

DIAS, Jaqueline e LAUREANO, Lourdes (orgs). Farmacopéia Popular do Cerrado. Articulação Pacari, 2009.

FLANDRIN, Jean Louis e MONTANARI, Maximo (orgs). História da Alimentação. São Paulo: Estação Liberdade, 1998.

KIPLE, Kenneth F. Uma história saborosa do mundo. Lisboa/Oeiras: Casa das Letras, 2008. 
PORTELA, Flávia (org.). Gula d'África: o sabor africano na mesa brasileira. Brasília: SENAC, 2007.

PRANDI, Reginaldo (org.). Encantaria Brasileira: o livro dos mestres, caboclos e encantados. Rio de Janeiro: Pallas, 2001.

SANTOS, Maria Estella de A.; PEIXOTO, Graziela D. O que as folhas cantam (para quem canta folha). Brasília: Instituto Nacional de Ciência e Tecnologia de Inclusão no Ensino Superior e na Pesquisa, 2014.

SOUMONNI, Elisée. Daomé e o mundo atlântico. Amsterdan: SEPHIS e Rio de Janeiro: Centro de Estudos Afro-Asiáticos da UCAM, 2001.

VERGER, Pierre. Fluxo e refluxo do tráfico de escravos entre o golfo do Benin e a Bahia de Todos os Santos: dos séculos XVII a XIX. São Paulo: Corrupio, 1987.

VOGEL, Arno; MELLO, Marco A. da Silva; BARROS, José F. de. A galinha d'angola: iniciação e identidade na cultura afro-brasileira. Rio de Janeiro: Pallas, 2001.

Recebido em: 05/05/2019

Aceito em: 13/05/2019 